\title{
Inhibition of Lipopolysaccharide-Stimulated Neuro- Inflammatory Kuntze in BV-2 Microglial Cell Mediators by Tetragonia tetragonoides (Pall)
}

\author{
Sung-Gyu Lee and Hyun Kang* \\ Department of Medical Laboratory Science, College of Health Science, Dankook University, Cheonan-si, Chungnam, 330-714, \\ Republic of Korea \\ *For correspondence: Email: hyunbio@gmail.com, hkang@dankook.ac.kr; Tel: 82-41-550-1452; Fax: 82-41-559-7934
}

\begin{abstract}
Purpose: To investigate the in vitro antioxidant and anti-neuroinflammatory effects of Tetragonia tetragonoides (Pall.) Kuntze extract (TKE) in lipopolysaccharide (LPS)-stimulated BV-2 microglial cells. Methods: To evaluate the effects of TKE, LPS-stimulated BV microglia were used and the expression and production of inflammatory mediators, namely, nitric oxide (NO), inducible NO synthase (iNOS) and tumor necrosis alpha (TNF- $\alpha$ ) were evaluated. Antioxidant activity of TKE was measured using 1, 1diphenyl-2-picryl-hydrazyl (DPPH) assay. Cell viabilities were estimated by 3-(4, 5-dimethylthiazol-2-yl)2, 5- diphenyl-tetrazolium bromide (MTT) assay.

Results: TKE significantly suppressed LPS-induced production of NO ( $p<0.001$ at 20, 40, 80 and 100 $\mu \mathrm{g} / \mathrm{ml}$ ) and expression of iNOS in BV-2 cells. TKE also suppressed LPS-induced increase in TNF- $\alpha$ level ( $p<0.001$ at $100 \mu \mathrm{g} / \mathrm{ml})$ in BV-2 cells. In addition, DPPH-generated free radicals were inhibited by TKE in a concentration-dependent manner.

Conclusion: The results suggest that TKE can be explored as a potential therapeutic agent for regulating microglia-mediated neuroinflammatory responses observed in several neurodegenerative diseases.
\end{abstract}

Keywords: Tetragonia tetragonoides, Anti-oxidant, Anti-inflammatory, Neurodegenerative diseases, Microglial cells, Lipopolysaccharide

Tropical Journal of Pharmaceutical Research is indexed by Science Citation Index (SciSearch), Scopus, International Pharmaceutical Abstract, Chemical Abstracts, Embase, Index Copernicus, EBSCO, African Index Medicus, JournalSeek, Journal Citation Reports/Science Edition, Directory of Open Access Journals (DOAJ), African Journal Online, Bioline International, Open-J-Gate and Pharmacy Abstracts

\section{INTRODUCTION}

Tetragonia tetragonoides (Pall.) Kuntze ( $T$. tetragonoides) is a medicinal herb widely grown along the seashores of the Pacific region, South America, Japan, Southeast China (including Norfolk and Lord Howe Islands), New Zealand, Australia, Tasmania, the Kermadec Islands, New Caledonia, Hawaii, and other Pacific Islands [1]. Pharmacologically, $T$. tetragonoides was reported to be used for migraine, gastric ulcers, stomach cancer, gastritis, septicemia and asthma[2,3]. However, studies on its beneficial effects on microglia-
neuroinflammatory diseases have not been reported.

Neuro-inflammation mediated by microglial activation appears to play an essential role in the pathogenesis of neurodegenerative diseases [4]. It is well documented that activated microglia releases proinflammatory mediators and free radicals which may participate progressive neurodegeneration. Therefore early attenuation of activated microglia and the neuroinflammatory 
processes can attenuate the severity of neurodegeneration [5].

Mounting evidence indicate that microbial endotoxins like LPS can directly activate microglia triggering the production of proinflammatory mediators, such as nitric oxide (NO), inducible NO synthase (iNOS), interleukins (IL) and tumor necrosis factor (TNF)- $\alpha$ [6-8]. Therefore, LPS-induced stimulation to microglia might be used as an important tool for evaluating the changes caused by activated microglia in vitro. Studies have shown that anti-oxidant and anti-inflammatory agents may inhibit microglial activation and thus protect against neuronal cell death seen in various neurodegenerative disorders $[7,8]$. In this study we evaluated the in vitro antioxidant potential and antineuroinflammatory properties of $T$. tetragonoides extract (TKE) in LPS-stimulated BV-2 microglial cells.

\section{EXPERIMENTAL}

\section{Materials}

The antibodies against iNOS and $\beta$-actin were purchased from Cell Signaling Technology INC. (Beverly, MA, USA).

\section{Preparation of TKE}

$T$. tetragonoides was collected from the western coast region in South Korea. The plant was authenticated by a Taxonomist, Dr. Kim Jong Bo at Konkuk University, South Korea and a voucher specimen (SM-KU2013) was stored in the institution's Biomedical and Health Sciences Department herbarium for future reference. To obtain the $S$. maritima extract, the dried plant material was ground in a mixer and defatted three times with three volumes of ethanol. The concentration of ethanol residue was extracted with absolute ethanol at 1:10 ratio $(w / v)$ for $2 \mathrm{~h}$ in heating mantle at $70-80{ }^{\circ} \mathrm{C}$. The supernatant was filtered and concentrated in vacuum evaporator system at $50{ }^{\circ} \mathrm{C}$. For further fractionation, the alcoholic extract $(500 \mathrm{mg})$ was partitioned into hexane, chloroform and ethyl acetate (EA) to furnish 110.5, 16.6 and 174.6 $\mathrm{mg}$, respectively. The EA fraction of TKE, was redissolved in distilled water to evaluate for its antineuroinflammatory and anti-oxidant activities.

\section{DPPH radical scavenging activity}

The anti-oxidant activity of the TKE was determined using the stable radical 2, 2-diphenyl1-picrylhydrazyl (DPPH, Sigma-Aldrich, St. Louis, MO, USA). Freshly prepared DPPH solution was taken in test tubes and the indicated concentrations of TKE $(0.01,0.1$ and $1 \mathrm{mg} / \mathrm{mmL})$ were added to the respective test tubes and made up to the final volume $(5 \mathrm{ml})$. Thirty minutes later, the absorbance was read at 517 $\mathrm{nm}$ using JES-FA ESR UV spectrometer (Jeol Ltd, Tokyo, Japan). Control was a sample containing the same volume but without TKE. Methanol was served as blank. The activity $(C)$ of the sample was calculated as in Eq 1.

$\mathrm{C}=\{(\mathrm{A} 1-\mathrm{A} 2) / \mathrm{A} 1\} 100$

where $\mathrm{A} 1$ is the absorbance of the control, and $\mathrm{A} 2$ is the absorbance of the extract [9]. $\mathrm{IC}_{50}$ values were extrapolated from inhibition plots.

\section{Cell cultures and evaluation of cell viability}

BV-2 microglia cells were cultured at $37{ }^{\circ} \mathrm{C}$ in 5 $\% \mathrm{CO}_{2}$ in DMEM (Invitrogen, Carlsbad, CA, USA) supplemented with $5 \%$ FBS (Hyclone, Logan, UT, USA) and antibiotics (Invitrogen). In all experiments, cells were pre-treated with the indicated concentrations of SM-EA extract for $1 \mathrm{~h}$ before the addition of $1 \mu \mathrm{g} / \mathrm{mL}$ LPS (SigmaAldrich, St. Louis, MO, USA) in serum free DMEM. An equal volume of sterile water was added to all control treatments. Cell viability was determined by 3-(4, 5-dimethylthiazol-2-yl)-2,5diphenyltetrazolium bromide (MTT) assay as described previously [10]. Cells were incubated with various concentrations of TKE for $24 \mathrm{~h}$ followed by MTT for $4 \mathrm{~h}$, and then $100 \mu \mathrm{L}$ of isopropanol (in $0.04 \mathrm{NM}$-hydrochloric acid) was added to dissolve the formazan crystals. The absorbance was read at $570 \mathrm{~nm}$ using Anthos 2010 spectrophotometer (Salzburg, Austria). Cell viability was calculated as relative absorbance compared to control.

\section{Nitric oxide assay}

The amount of stable nitrite, the end product of NO generation by activated microglia was determined by a colorimetric assay as previously described [10]. Culture supernatant $(50 \mu \mathrm{L})$ was mixed with an equal volume of Griess reagent and incubated at room temperature for $10 \mathrm{~min}$. The absorbance at $540 \mathrm{~nm}$ was read in a Power Wavex Microplate Scanning spectrophotometer (Bio-Tek Instrument, Winooski, VT, USA). Nitrite concentration was determined by extrapolation from a sodium nitrite standard curve.

\section{Western blot analysis}

Cells were washed three times in cold PBS and lysed in $50 \mathrm{mM}$ Tris- $\mathrm{HCl}$ buffer, $\mathrm{pH} 7.4$, containing $1 \%(\mathrm{v} / \mathrm{v})$ NP-40, $0.25 \%$ sodium 
deoxycholate, $150 \mathrm{mM} \mathrm{NaCl}, 1 \mathrm{mM}$ EDTA, 25 $\mathrm{mM} \mathrm{NaF}, 2 \mathrm{mM} \mathrm{Na}_{3} \mathrm{VO}_{4}$ and protease inhibitor cocktail (Complete MiniTM, Roche, Mannheim, Germany) at $4{ }^{\circ} \mathrm{C}$. The lysate was clarified by centrifugation at $10,000 \mathrm{~g}$ for $20 \mathrm{~min}$ at $4{ }^{\circ} \mathrm{C}$ to remove insoluble components. Protein concentration was determined using BioRad DC protein assay kit. Equal amounts of protein were mixed 4:1 (v:v) with an SDS sample buffer and then boiled for $5 \mathrm{~min}$. On pre-cast $10 \%$ SDSPAGE gels, $10 \mu \mathrm{L}$ was run. The protein was transferred to NC membrane (S\&S, Dassel, Germany) and blocked with $5 \%$ non-fat dry milk in TBS. To detect protein expression, the blots were probed with the specific antibodies of iNOS and $\beta$-actin followed by the secondary antibodies coupled to horseradish peroxidase (Bio-Rad, Herculus, CA, USA) with $\beta$-actin as internal control. The immunoreactive proteins on the membrane were detected by chemiluminescence using the West-Save substrate (Lab-Frontier, Seoul, Korea) on X-ray film.

\section{Assay of TNF- $\alpha$}

BV-2 microglia cells $\left(1 \times 10^{5}\right.$ cells/well $)$ were cultured on 96 well plates and treated with the TKE at indicated concentrations for $1 \mathrm{~h}$ and stimulated with LPS $(1 \mu \mathrm{g} / \mathrm{ml})$. At $4 \mathrm{~h}$ post LPS treatment, the cells were collected and the supernatants were evaluated for TNF- $\alpha$ level using a murine TNF- $\alpha$ ELISA kit from BD Biosciences (San Jose, CA, USA) according to the manufacturer's instructions.

\section{Statistical analysis}

All data are presented as mean \pm S.E.M of at least three independent experiments. Statistical analyses were performed using SAS statistical software (SAS Institute, Cray, NC, USA) using one-way analysis of variance, followed by Dunnett's multiple range tests. $P<0.05$ was considered statistically significant.

\section{RESULTS}

\section{Effect of TKE on DPPH radical scavenging activity}

As shown in Fig. 1A, TKE exhibited significant $\mathrm{DPPH}$ radical scavenging activity in a dosedependent manner with a maximum effect at $1 \mathrm{mg} / \mathrm{ml}(p<0.001)$. The concentration needed for $50 \%$ inhibition of DPPH radicals was found to be approximately at IC50 was $0.42 \mathrm{mg} / \mathrm{ml}$. The ESR spectroscopy data at $0.01,0.1$ and $1 \mathrm{mg} / \mathrm{ml}$ was represented in Fig 1B.

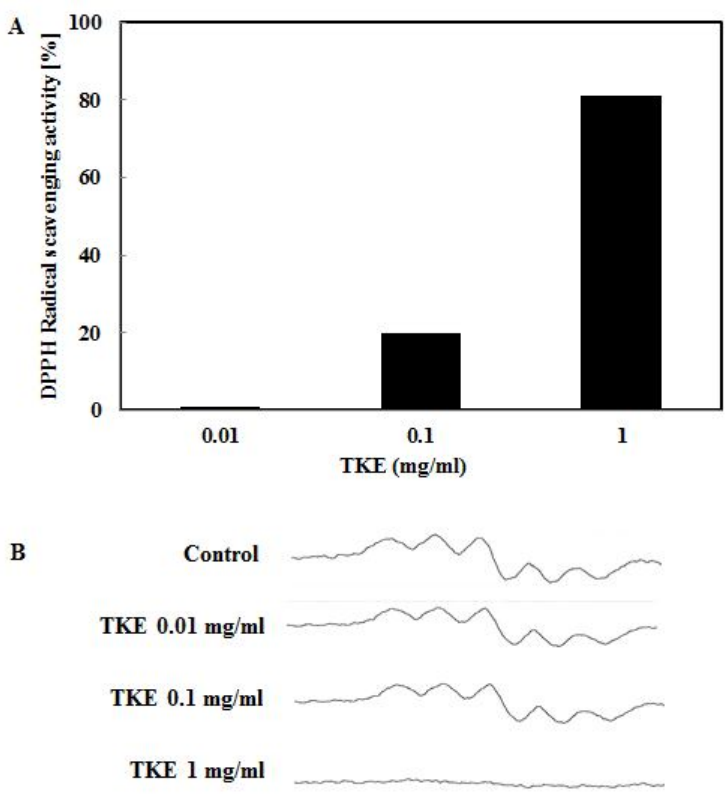

Fig 1: Effect of TKE on DPPH radical scavenging activity

\section{Effect of SM-EA extracts on LPS-induced NO production}

NO production by LPS-activated cells was found to be significantly inhibited by TKE extract in a concentration-dependent manner (Fig 2). The maximum effect was observed at 80 and 100 $\mu \mathrm{g} / \mathrm{ml}(p<0.001)$. TKE extract treatment did not exhibit any significant cytotoxicity in BV-2 microglial cells for $24 \mathrm{~h}$ at concentrations up to $100 \mu \mathrm{g} / \mathrm{ml}$, and in all cases the viability was found above $93 \%$ by MTT assay (Fig 3).

\section{Effect of TKE extract on LPS-induced expressional levels of iNOS}

LPS (1 $\mu \mathrm{g} / \mathrm{ml}$ ) strongly induced BV-2 cells showing an increased expression of iNOS. However, treatment with TKE at 50 and 100 $\mu \mathrm{g} / \mathrm{ml}$ concentrations exhibited a broad spectrum of inhibitory effect on the expression of iNOS induced by LPS in BV-2 cells (Fig. 4). . These results indicated that TKE may be potential inhibitor for iNOS.

\section{Effect of SM-EA extract on TNF- $\alpha$ production in LPS-stimulated BV-2 cells}

As shown in Fig. 5, TNF- $\alpha$ levels increased significantly after LPS treatment $(1 \mu \mathrm{g} / \mathrm{ml})$ when compared to those in untreated cells $(p<0.001)$. However, TKE significantly inhibited TNF- $\alpha$ production in a concentration-dependent manner in LPS-stimulated BV-2 cells $(p<0.05$ at 40 $\mu \mathrm{g} / \mathrm{ml}$ and $p<0.001$ at $100 \mu \mathrm{g} / \mathrm{ml}$, respectively). 


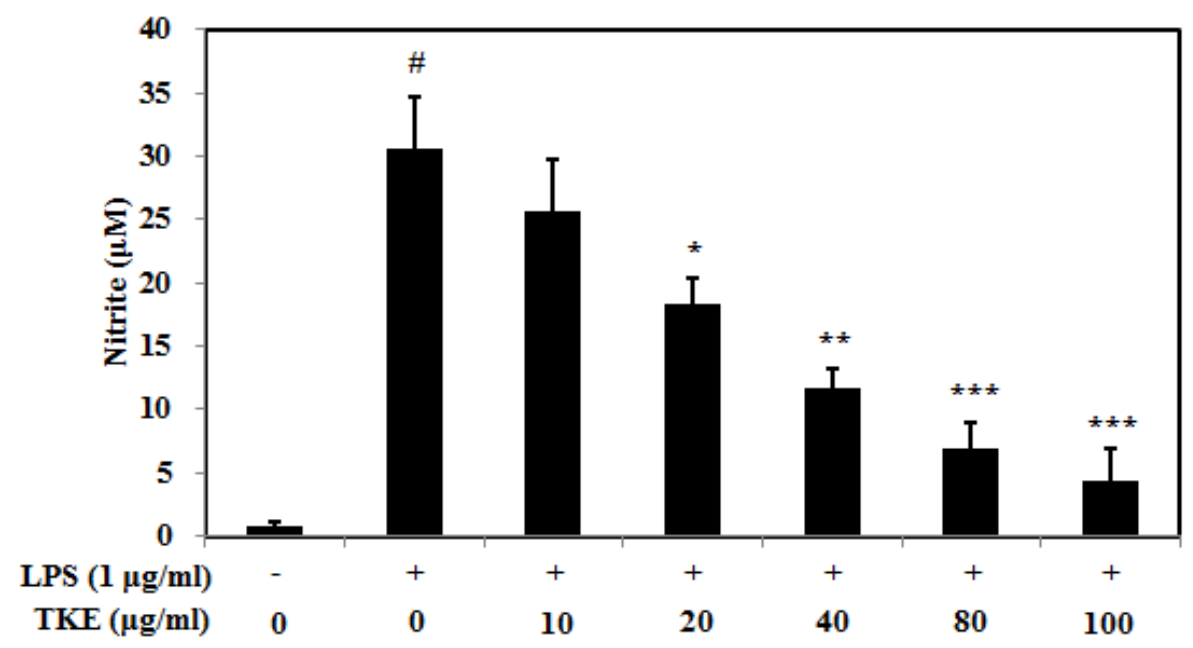

Fig 2: Effect of TKE on NO Production in LPS-stimulated BV-2 microglial cells. BV-2 cells were treated with SMEA extract at various concentrations $(10,20,40,80$, and $100 \mu \mathrm{g} / \mathrm{ml})$ with or without LPS $(1 \mu \mathrm{g} / \mathrm{ml})$ for $4 \mathrm{~h}$. The nitrite in the culture supernatant was evaluated using Griess reagent. Data are presented as the mean \pm S.E.M. $(n=3)$ for three independent experiments. ${ }^{\sharp} p<0.001$, when compared with control group. ${ }^{*} p<0.05,{ }^{* *} p<0.01$ and ${ }^{* * *} p<0.001$, by one-way analysis of variance, followed by Dunnett's multiple range tests

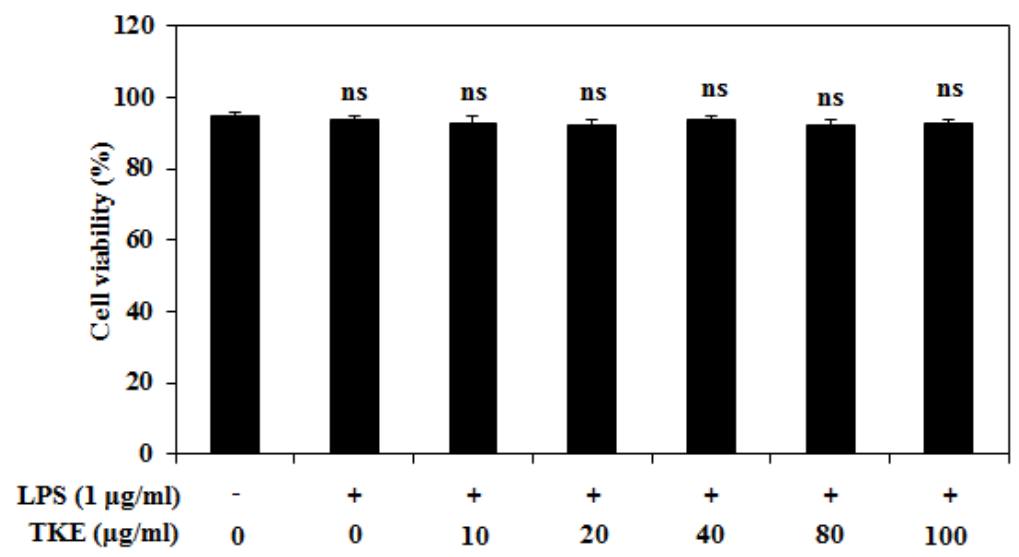

Fig 3: Effects of TKE on the viability of BV-2 microglial cells. Viability in TKE treated cells was determined using MTT assay. The results are displayed as percentage of control samples. Data are presented as the mean \pm S.E.M. $(n=3)$ for three independent experiments. NS Not significant

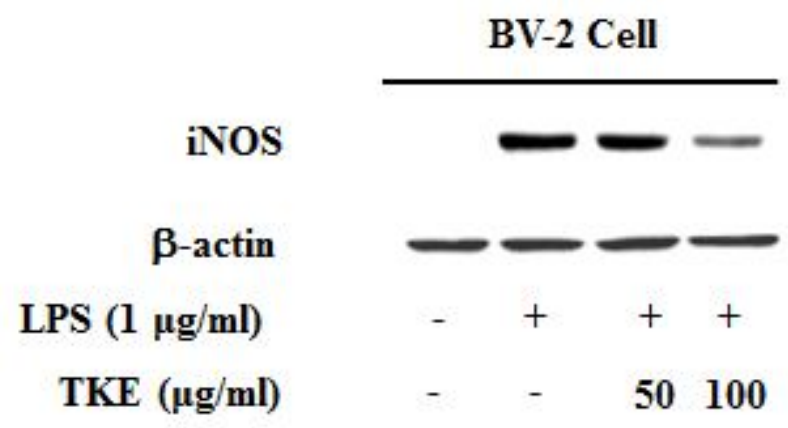

Fig 4: Effect of TKE on iNOS protein expressional levels in LPS-stimulated BV-2 microglial cells. The expression levels of iNOS production in the LPS-stimulated BV-2 cells by indicated concentrations (50 and $100 \mu \mathrm{g} / \mathrm{ml}$ ) of the TKE was monitored by immunoblot analyses with the specific antibodies against iNOS. The internal control used was $\beta$-actin. TKE $=$ Tetragonia tetragonoides (Pall.) Kuntze ethanol extract 


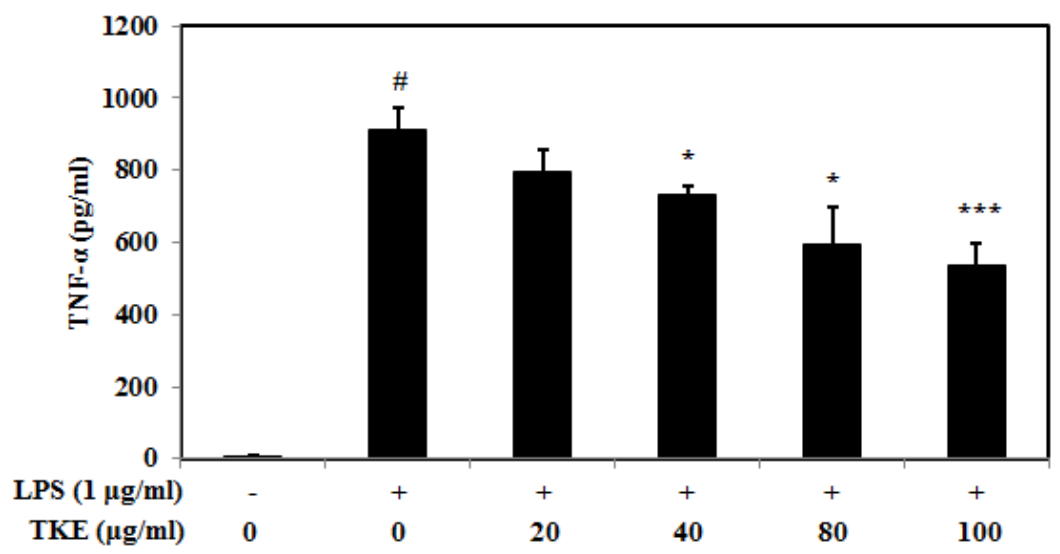

Fig 5: Effect of TKE on TNF- $\alpha$ production in LPS-stimulated BV-2 microglial cells. Suppression of proinflammatory cytokine TNF- $\alpha$ expression by TKE was measured with ELISA test. BV-2 cells were treated with TKE at 20, 40, 80 and $100 \mu \mathrm{g} / \mathrm{ml}$ with or without LPS $(1 \mu \mathrm{g} / \mathrm{ml})$ for $4 \mathrm{~h}$. The TNF- $\alpha$ in the culture supernatant was evaluated using a murine TNF- $\alpha$ ELISA kit. Data are presented as the mean \pm S.E.M. $(n=3)$ for three independent experiments. ${ }^{\#} p<0.001$, when compared with control group. ${ }^{*} p<0.05$, and ${ }^{* * *} p<0.001$, when compared with LPS alone group by Student t-test

\section{DISCUSSION}

In the present study, we report that TKE significantly inhibited production of NO, suppressed the expression of iNOS protein level and attenuated the increased levels of TNF- $\alpha$ production in LPS-simulated BV-2 microglial cells. In addition, TKE exhibited significant antioxidant activity evaluated by DPPH free radical scavenging method. Free radicals and reactive oxygen species (ROS) are important causative factors in the development of agerelated neuro-inflammatory and neurodegenerative diseases [11]. Thus neutralization by antioxidants and radical scavengers can reduce neuroinflammation. It is well known that DPPH radical assay is one of the widely used methods for evaluating the free radical scavenging activities of several antioxidants [12]. Earlier studies revealed that Tetragonia tetragonoides (Pall) Kuntze possess strong antioxidant polyphenolic, vitamin $\mathrm{C}$, and sterol compounds $[2,3]$. In our present study, the TKE also exhibited significant free radical scavenging effect indicating that the TKE might contain potential antioxidant agents. Since antioxidants reduce neuroinflammation [11], TKE extract was used to evaluate its anti-neuroinflammatory activity in LPS-stimulated BV-2 microglial cells.

A significant number of reports have established that inflammatory mediators, including $\mathrm{NO}$ and iNOS are responsible for the symptoms of many neuroinflammatory diseases. It is well documented that microglia produces $\mathrm{NO}$ and increase the iNOS expression in response to proinflammatory stimuli LPS leading to increased inflammatory reaction [13]. Therefore, agents that decrease NO production and iNOS have appreciable therapeutic effect in the treatment of several neuroinflammatory diseases $[13,14]$. Our results clearly show that TKE attenuated LPSinduced iNOS expression and downstream NO production.

Pro-inflammatory cytokines such as TNF- $\alpha$ cause potent activation of iNOS gene expression in rodent glial cells and muscle cells [15]. Microglial cell activation by LPS produces various cytokines including TNF- $\alpha$ leading to the attraction of neutrophils and the accumulation of neutrophil-secreted proteases and ROS at the site of inflammation. Data from our study show that TKE may act by suppressing the increased production of TNF- $\alpha$ thereby inhibiting NO production and iNOS expression levels in LPSstimulated BV-2 cells indicating that TKE may be an effective anti-neuroinflammatory agent.

\section{CONCLUSION}

TKE plays an important role in attenuating neuroinflammatory responses in LPS-stimulated BV-2 microglial cells. The anti-neuroinflammatory effect of TKE may be due to its regulatory actions on proinflammatory cytokines such as TNF- $\alpha$. The strong antioxidant effects exhibited by TKE may also be involved in exerting the effect. Based on these findings, TKE is a promising candidate for the treatment of neuroinflammation-mediated neurodegenerative disorders. 


\section{REFERENCES}

1. Kato $M$, Takeda $T$, Ogihara $Y$, Shimizu $M$, Nomura $T$, Tomita Y. Studies on the structure of polysaccharide from Tetragonia Tetragonoides. Chem Pharm Bull 1985; 33(9): 3675-3680.

2. Cho BS, Lee JJ, Ha JO, Lee MY. Physicochemical composition of Petasites japonicus S. Et Z. Max. Korean J Food Preserv 2006; 13(5): 661-667.

3. Lee MA, Choi HJ, Kang JS, Choi YH, Joo WH. Antioxidant activities of the solvent extracts from Tetragonia tetragonioides. J Life Sci 2008; 18(2): 220-227.

4. JK Patra1, NK Dhal2, HN Thatoi3*. In vitro bioactivity and phytochemical screening of Suaeda maritima (Dumort): A mangrove associate from Bhitarkanika, India. Asian Pacific J Trop Med 2011; 4: 727-734.

5. Perry VH, Gordon S. Macrophages and microglia in the nervous system. Trends Neurosci 1988; 11: 273-277.

6. Liu B, Hong J.S. Role of microglia in inflammationmediated neurodegenerative diseases: mechanisms and strategies for therapeutic intervention. $J$ Pharmacol Exp Ther 2003; 304: 1-7.

7. Xie Q.W., Kashiwabara Y, Nathan C. Role of transcription factor NF-kappa B/Rel in induction of nitric oxide synthase J Biol Chem 1994; 269 (7) : 4705-4708.

8. Agullo G, Gamet-Payrastre L, Manenti S, Viala C, Rémésy $\mathrm{C}$, Chap $\mathrm{H}$, et al. Relationship between flavonoid structure and inhibition of phosphatidylinositol 3-kinase: a comparison with tyrosine kinase and protein kinase $C$ inhibition. Biochem Pharmacol 1997; 53: 2087-2094.

9. Araki E, Forster C, Dubinsky JM, Ross ME, ladecola C. Cyclooxygenase-2 inhibitor NS-398 protects neuronal cultures from lipopolysaccharide-induced neurotoxicity. Stroke 2001; 32:2370-2375.

10. Nanjo F, Goto K, Seto R, Suzuki M. Scavenging effects of tea catechins and their derivatives on 1,1-diphenyl2-picrylhydrazyl radical. Free Radic Biol Med 1996; 21: 895-902.

11. Kim BW, Koppula S, Kim IS, Lim HW. Antineuroinflammatory activity of Kamebakaurin from Isodon japonicus via inhibition of c-Jun NH-terminal kinase and p38 mitogen-activated protein kinase pathway in activated microglial cells. J Pharmacol Sci 2011; 116: 296-308.

12. Finkel T, Holbrook NJ. Oxidants, oxidative stress and the biology of ageing. Nature 2000; 408: 239-247.

13. Sanches-Moreno C, Plaza L, Ancos B, Cano MP. Nutritional characterization of commercial trnaditional pasteurized tomato juices: carotenoids, vitamin and radical-scavenging activity. Food Chem 2006; 98: 749-756.

14. Tuttolomondo A, Di Raimondo D, di Sciacca R, Pinto A, Licata G. Inflammatory cytokines in acute ischemic stroke. Curr Pharm Des. 2008; 14: 3574-3589.

15. Merrill JE, Benveniste EN. Cytokines in inflammatory brain lesions: helpful and harmful. Trends Neurosci. 1996; 19: 331-338. 